\title{
Short Sleep Duration is a Risk of Incident Nonalcoholic Fatty Liver Disease: A Population-based Longitudinal Study
}

\author{
Takuro Okamura $^{1}$, Yoshitaka Hashimoto ${ }^{1}$, Masahide Hamaguchi ${ }^{1}$, Akihiro Obora ${ }^{2}$, Takao Kojima ${ }^{2}$, Michiaki Fukui $^{1}$
}

1) Department of

Endocrinology and

Metabolism, Kyoto Prefectural

University of Medicine,

Graduate School of Medical

Science, Kyoto

2) Department of

Gastroenterology, Asahi

University Hospital, Gifu, Japan

Address for correspondence: Masahide Hamaguchi, MD PhD Department of Endocrinology and Metabolism

Kyoto Prefectural University of Medicine

Graduate School of Medical Science

465, Kajii-cho, Kawaramachi-

Hirokoji, Kamigyo-ku,

Kyoto 602-8566, Japan

mhama@koto.kpu-m.ac.jp
Received: 28.11.2018

Accepted: 22.02.2019

\section{ABSTRACT}

Background \& Aims: Previous cross-sectional studies revealed that short sleep duration has a close relationship with the presence of non-alcoholic fatty liver disease (NAFLD). We aimed to investigate the association between sleep duration and incident NAFLD.

Methods: In this historical cohort study of 12,306 participants (5,848 men and 6,458 women), we investigated the effect of sleep duration on incident NAFLD. NAFLD was defined as having fatty liver diagnosed by abdominal ultrasonography in the participants who consumed ethanol less than $30 \mathrm{~g} /$ day for men and 20 $\mathrm{g} /$ day for women. We divided the participants into four groups according to sleep duration: $>7,>6-7,>5-6$, and $\leq 5 \mathrm{~h}$. Cox proportional hazards models were performed to investigate the effect of sleep duration on incident NAFLD, adjusting for age, body mass index categories, alanine aminotransferase, triglycerides, high density lipoprotein-cholesterol, fasting plasma glucose, smoking status, alcohol consumption, systolic blood pressure, exercise.

Results: During the median 6.8-year follow-up for men and the 7.0-year follow-up duration for women, 2,280 participants (1,581 men and 699 women) developed NAFLD. In Cox proportional hazards models, sleep duration of $\leq 5 \mathrm{~h}$ in both men and women were revealed to be a significant risk for incident NAFLD, compared to men and women with a sleep duration of $>7 \mathrm{~h}$ (men: hazard ratio $1.39,95 \%$ confidence interval $1.13-1.72, \mathrm{p}=0.002$; women; $1.46,1.05-2.04, \mathrm{p}=0.023$ ).

Conclusion: This is the first study showing that short sleep duration was a risk factor for incident NAFLD.

Key words: cohort study - non-alcoholic fatty liver disease - sleep duration - epidemiology.

Abbreviations: ALT: alanine aminotransferase; BMI: body mass index; CI: confidence interval; HDL: high density lipoprotein; HR: hazard ratio; NAFLD: non-alcoholic fatty liver disease; NAGALA: NAfld in the Gifu Area Longitudinal Analysis; OSAS: obstructive sleep apnea syndrome; TG: triglycerides.

\section{INTRODUCTION}

The proportion of adults whose sleep duration is less than 6 hours has increased from $34.7 \%$ in 2005 to $39.5 \%$ in 2015 in Japan [1]. Several longitudinal studies have demonstrated that short sleep duration and insomnia increased the risk of incident lifestyle diseases such as obesity [2], hypertension [3], diabetes, metabolic syndrome [4], cardiovascular disease [5] and mental illness such as depression [6]. Reported mechanisms of short sleep duration on incident various lifestyle diseases were: modulation of sleep caused irregular habits in diet and exercise $[7,8]$, decreased leptin and increased ghrelin, both of which influence appetite and energy balance $[9,10]$ and influence the hormones of hypothalamic-pituitary-adrenal system [11]. Therefore, early detection and resolution of sleep impairment could prevent the lifestyle disease.

The number of patients with non-alcoholic fatty liver disease (NAFLD), caused by ectopic fat accumulation in the liver has increased to $20-30 \%$ in Japan [12]. Non-alcoholic fatty liver disease is not only one of the common causes of chronic liver disease [13], but also the cause of metabolic syndrome [14], type 2 diabetes [15] chronic kidney disease [16] and cardiovascular disease [17]. Therefore, the prevention and treatment of NAFLD are important for the prevention of further diseases such as type 2 diabetes, chronic kidney disease and cardiovascular disease. 
Previous meta-analyses investigated the association between sleep duration or quality and the prevalence of NAFLD, and showed that short sleep duration was associated with NAFLD prevalence [18-20]. However, a few studies investigated the association between sleep duration and incident NAFLD [21] and evidenced that long sleep duration was associated with incident NAFLD. Thus, the relationship between sleep duration and NAFLD remains controversial.

Therefore, we focused especially on sleep duration and investigated the association between sleep duration and incident NAFLD in this retrospective cohort study.

\section{METHODS}

\section{Study participants and study design}

In this population-based longitudinal analysis of a medical examination program at the Asahi University Hospital (Gifu, Japan), we performed an investigation of the impact of sleep duration on the risk of incident NAFLD, using the NAGALA (NAfld in the Gifu Area, Longitudinal Analysis) database. The aim of this medical examination program is to detect chronic diseases and their risk factors, and to promote public health. This type of medical service called „a human dock” is very popular in Japan. In this center, more than 8,000 medical examinations are performed annually, $60 \%$ of them being monitoring visits, once or twice a year and $40 \%$ of them being done on new subjects. The details of NAGALA study and medical examination programs were expressed elsewhere [22]. In this study, we selected the data of the individuals who participated in this medical examination program from 2004 till 2015. The exclusion criteria were: the use of any kind of medication, known liver disease and fatty liver at baseline examination, ethanol consumption over $30 \mathrm{~g} /$ day for men and $20 \mathrm{~g} /$ day for women [15] and the participants in whom the data, including sleep duration, exercise habit, HDL-cholesterol, alcohol consumption, smoking status, were missed. Known liver disease was defined as viral hepatitis (assessment of hepatitis B antigen and hepatitis C antibody). The study followed the Declaration of Helsinki being approved by the Ethics Committee of Asahi University Hospital. In addition, written informed consent was obtained from each participant.

\section{Data collection and measurements}

The medical history and the data on smoking, alcohol habits, physical activity and sleep duration were obtained by a standardized self-administered questionnaire [22]. We evaluated alcohol consumption by asking about the type and amount of alcohol consumption per week during the prior month, then estimating the mean ethanol intake per week. We also categorized the participants into three groups by smoking status: never-, ex-, or current smoker. We investigated the participants' recreational and sports activities. We defined regular exercisers as participants who played any type of sports over one time per week regularly [23].

\section{Definition of NAFLD}

Abdominal ultrasonography, performed by trained technicians, was used for diagnosing fatty liver [24]. Gastroenterologists checked the images and diagnosed fatty liver being blind to the medical record of the participants. Liver brightness and liver contrast among the four known criteria (hepatorenal echo-contrast, liver brightness, deep attenuation and vascular blurring) were used for diagnosing fatty liver [24]. We excluded the participants who consumed ethanol over 30 $\mathrm{g} /$ day for men and $20 \mathrm{~g} /$ day for women [15].

\section{Statistical analysis}

We analyzed the data using the JMP ver. 13.0 software (SAS, Cary, NC, USA), and p-values $<0.05$ were considered significant. Values were expressed as mean (SD) for continuous variables and number (\%) for categorical variables. First, we divided the participants into men and women because the number of participants with development of NAFLD differed in relation to gender. Moreover, we categorized the participants into four groups according to sleep duration: $\leq 5 \mathrm{~h}$ (the shortest), $>5-6 \mathrm{~h},>6-7 \mathrm{~h}$ and $>7 \mathrm{~h}$ (the longest), which were often used in previous studies $[2,18,25]$. We also categorized the participants into four groups according to body mass index (BMI): lean, BMI $<18.5 \mathrm{~kg} / \mathrm{m}^{2}$; normal body weight, $\geq 18.5-<23 \mathrm{~kg} / \mathrm{m}^{2}$; overweight, $\geq 23-<25 \mathrm{~kg} / \mathrm{m}^{2}$ obesity, $\geq 25 \mathrm{~kg} /$ $\mathrm{m}^{2}[26,27]$. Categorical variables were compared among the groups by Pearson's qui-squared test, and continuous variables were compared by one-way analysis of variance and the Tukey honestly significant difference test, respectively.

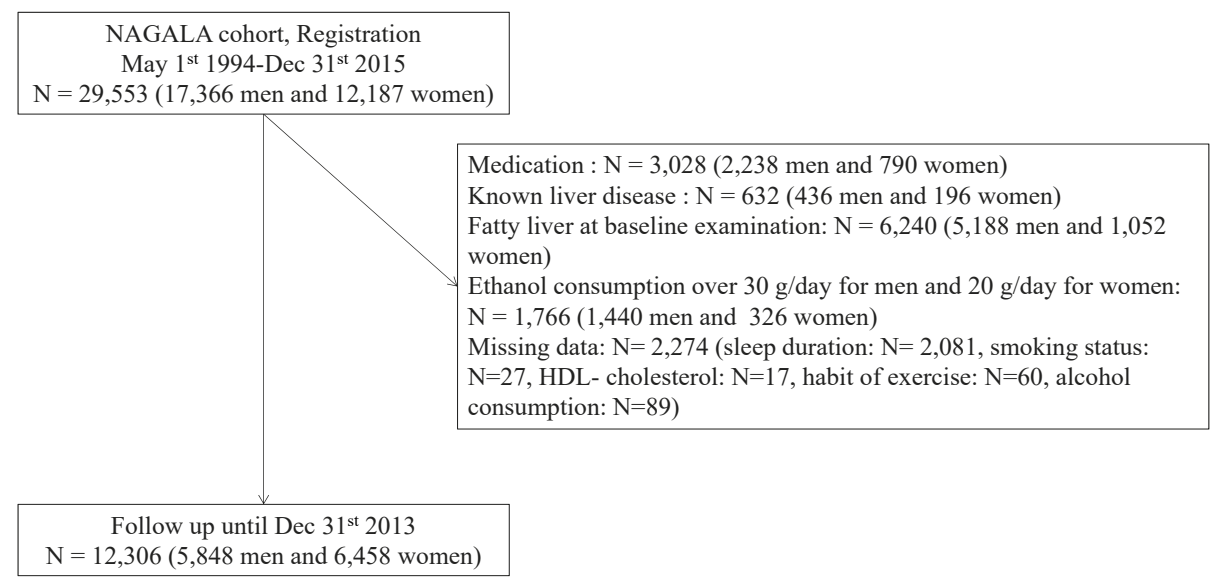

Fig. 1. Study flow diagram for the registration of participants. NAGALA: NAfld in Gifu Area, Longitudinal Analysis; NAFLD: non-alcoholic fatty liver disease. 
We used Kaplan-Meier analysis for a graphical presentation of time to incident NAFLD, and log-rank test to evaluate difference among the groups according to sleep duration. We performed a Bonferroni correction and considered that a $\mathrm{p}$ value $<0.0083$ was statistically significant in the log-rank test.

Cox proportional hazards models were used to calculate adjusted hazard ratio (HR) and 95\% confidence interval (CI) for incident NAFLD according to four categories of sleep duration. We adjusted for age, BMI categories, alanine aminotransferase (ALT), triglycerides (TG), high-density lipoprotein (HDL) cholesterol, smoking status, exercise habit, alcohol consumption, systolic blood pressure, fasting plasma glucose and sleep duration categories. We performed Cox hazards regression adjusted for BMI and sleep duration as continuous variables.

\section{RESULTS}

From May 1st 1994 to December 31st 2015, a total of 29,553 (17,366 men and 12,187 women) participants were registered in the NAGALA cohort. After we excluded 14,981 participants, 12,306 (5,848 men and 6,458 women) participants were introduced in this study (Fig. 1).

The baseline characteristics of the participants are summarized in Tables I and II. Women with sleep duration of $>7 \mathrm{~h}$ (the longest) were significantly younger and had lower BMI than the other groups. On the other hand, men with the longest sleep duration and $>6-7 \mathrm{~h}$ had significantly lower BMI than men with sleep duration of $\leq 5 \mathrm{~h}$ (the shortest), and men with the shortest sleep duration were significantly younger than the other groups.

Table I. Characteristics of study participants of the cohort study at the baseline examination according to sex

\begin{tabular}{|c|c|c|c|}
\hline & Men & Women & $\mathrm{p}$ value \\
\hline Number & 5,848 & 6,458 & \\
\hline Age (years) & $42.4(8.9)$ & $41.6(8.4)$ & $<0.001$ \\
\hline Body mass index $\left(\mathrm{kg} / \mathrm{m}^{2}\right)$ & $22.1(2.4)$ & $20.7(2.6)$ & $<0.001$ \\
\hline Body mass index categories & & & $<0.001$ \\
\hline Lean & $372(6.4)$ & $1,236(19.1)$ & \\
\hline Normal body weight & $3,421(58.5)$ & 4,175 (64.6) & \\
\hline Overweight & $1,389(23.8)$ & $675(10.5)$ & \\
\hline Obesity & $666(11.4)$ & $372(5.8)$ & \\
\hline Systolic blood pressure ( $\mathrm{mmHg}$ ) & $116.6(13.6)$ & $108.8(13.6)$ & $<0.001$ \\
\hline Diastolic blood pressure $(\mathrm{mmHg})$ & $73.1(9.5)$ & $67.3(9.3)$ & $<0.001$ \\
\hline Fasting plasma glucose $(\mathrm{mmol} / \mathrm{L})$ & $5.3(0.6)$ & $5.0(0.5)$ & $<0.001$ \\
\hline Hemoglobin Alc (\%) & $5.2(0.5)$ & $5.2(0.4)$ & 0.002 \\
\hline Triglycerides $(\mathrm{mmol} / \mathrm{L})$ & $1.0(0.7)$ & $0.7(0.4)$ & $<0.001$ \\
\hline High-density lipoprotein cholesterol $(\mathrm{mmol} / \mathrm{L})$ & $1.3(0.3)$ & $1.6(0.4)$ & $<0.001$ \\
\hline Triglycerides/High-density lipoprotein cholesterol ratio & $0.9(0.3)$ & $0.5(0.4)$ & $<0.001$ \\
\hline Creatinine $(\mu \mathrm{mol} / \mathrm{L})$ & $83.6(18.0)$ & $61.0(9.9)$ & $<0.001$ \\
\hline Estimated Glomerular filtration rate $\left(\mathrm{ml} / \mathrm{min} / 1.73 \mathrm{~m}^{2}\right)$ & $72.5(12.7)$ & $76.3(14.6)$ & $<0.001$ \\
\hline Aspartate aminotransferase (IU/L) & $18.2(6.7)$ & $16.2(8.7)$ & $<0.001$ \\
\hline Alanine aminotransferase (IU/L) & $20.2(10.3)$ & $14.1(12.2)$ & $<0.001$ \\
\hline Gamma-glutamyltransferase (IU/L) & $23.1(20.4)$ & $12.5(8.4)$ & $<0.001$ \\
\hline Smoking status & & & $<0.001$ \\
\hline Never smoker & $2,024(34.6)$ & $5,626(87.1)$ & \\
\hline Ex-smoker & $1,531(26.2)$ & $416(6.4)$ & \\
\hline Current smoker & $2,293(39.2)$ & $416(6.4)$ & \\
\hline Habit of exercise & $1,116(19.1)$ & $989(15.3)$ & $<0.001$ \\
\hline Alcohol consumption, g/wk & $53.6(57.9)$ & $13.2(28.1)$ & $<0.001$ \\
\hline Sleep duration & & & 0.03 \\
\hline$\leq 5 \mathrm{~h}$ & $889(15.2)$ & $1,039(16.1)$ & \\
\hline$>5-6 \mathrm{~h}$ & $2,377(40.6)$ & $2,733(42.3)$ & \\
\hline$>6-7 \mathrm{~h}$ & $2,068(35.4)$ & $2,128(33.0)$ & \\
\hline$>7 \mathrm{~h}$ & $514(8.8)$ & $558(8.6)$ & \\
\hline
\end{tabular}

Data are expressed as mean (SD) or number (\%) of subjects. Lean was defined $<18.5 \mathrm{~kg} / \mathrm{m}^{2}$, normal body weight was defined $\geq 18.5-<23 \mathrm{~kg} / \mathrm{m}^{2}$, overweight was defined $\geq 23-<25 \mathrm{~kg} / \mathrm{m}^{2}$ and obesity was defined $\geq 25 \mathrm{~kg} / \mathrm{m}^{2}$. p values by one-way analysis of variance for continuous variables and chi-squared test for categorical variables. 
Table II. Characteristics of study participants at the baseline examination according to sex and sleep duration

\begin{tabular}{|c|c|c|c|c|c|}
\hline Men & & & & & \\
\hline Sleep duration (h) & $\leq 5 \mathrm{~h}$ & $>5-6$ & $>6-7$ & $>7$ & $\mathrm{p}$ value \\
\hline Number & 889 & 2,377 & 2,068 & 514 & \\
\hline Age (years) & $40.5(8.1)$ & $41.8(8.5) \dagger$ & $43.4(9.1)^{\dagger, *}$ & $44.2(9.9)^{\dagger, *}$ & $<0.001$ \\
\hline Body mass index $\left(\mathrm{kg} / \mathrm{m}^{2}\right)$ & $22.4(2.4)$ & $22.2(2.4)$ & $22.1(2.5)^{\dagger}$ & $21.9(2.4)^{\dagger}$ & 0.002 \\
\hline Body mass index categories & & & & & 0.112 \\
\hline Lean & $53(6.0)$ & $135(5.7)$ & $149(7.2)$ & $35(6.8)$ & \\
\hline Normal body weight & $498(56.0)$ & $1,388(58.4)$ & $1,219(58.9)$ & $316(61.5)$ & \\
\hline Overweight & $222(25.0)$ & $585(24.6)$ & $465(22.5)$ & $117(22.8)$ & \\
\hline Obesity & $116(13.0)$ & $269(11.3)$ & $235(11.4)$ & $46(8.9)$ & \\
\hline Systolic blood pressure (mmHg) & $115.4(12.5)$ & $116.3(13.2)$ & $117.2(14.3)^{\dagger}$ & $117.5(14.2)^{\dagger}$ & 0.003 \\
\hline Diastolic blood pressure (mmHg) & $71.9(9.0)$ & $72.8(9.3)$ & $73.7(9.8)^{\dagger, *}$ & $73.8(9.3)^{\dagger}$ & $<0.001$ \\
\hline Fasting plasma glucose $(\mathrm{mmol} / \mathrm{L})$ & $5.4(0.8)$ & $5.3(0.6)$ & $5.3(0.6)$ & $5.3(0.9)$ & 0.109 \\
\hline HbAlc (\%) & $5.2(0.5)$ & $5.2(0.5)$ & $5.2(0.5)^{\ddagger}$ & $5.2(0.6)^{\ddagger}$ & 0.001 \\
\hline Triglycerides $(\mathrm{mmol} / \mathrm{L})$ & $1.0(0.6)$ & $1.0(0.6)$ & $1.1(0.7)^{\dagger, *}$ & $1.1(0.7)^{\dagger, *}$ & $<0.001$ \\
\hline HDL cholesterol (mmol/L) & $1.3(0.3)$ & $1.3(0.3)$ & $1.3(0.3)^{\dagger, *}$ & $1.3(0.3)^{\ddagger}$ & $<0.001$ \\
\hline TG/HDL ratio & $0.82(0.68)$ & $0.84(0.78)$ & $0.97(0.84)^{+, *}$ & $1.01(0.82)^{+, *}$ & $<0.001$ \\
\hline Creatinine $(\mu \mathrm{mol} / \mathrm{L})$ & $87.8(12.1)$ & $83.1(23.9)$ & $84.6(12.6)^{t, *}$ & $85.0(12.1)^{\dagger}$ & $<0.001$ \\
\hline $\operatorname{eGFR}\left(\mathrm{ml} / \mathrm{min} / 1.73 \mathrm{~m}^{2}\right)$ & $74.7(12.3)$ & $73.6(12.7)$ & $71.0(12.6)^{t, *}$ & $70.2(12.2)^{\dagger, *}$ & $<0.001$ \\
\hline AST (IU/L) & $18.1(6.4)$ & $18.1(6.7)$ & $18.4(6.7)$ & $18.4(7.0)$ & 0.566 \\
\hline $\operatorname{ALT}(\mathrm{IU} / \mathrm{L})$ & $20.3(9.9)$ & $20.5(9.8)$ & $20.1(10.5)$ & $19.6(12.6)$ & 0.313 \\
\hline GGT (IU/L) & $21.8(18.8)$ & $22.5(19.8)$ & $23.9(21.5)^{\dagger}$ & $24.3(20.4)$ & 0.012 \\
\hline Smoking status ${ }^{*}$ & & & & & $<0.001$ \\
\hline Never smoker & $347(39.0)$ & $872(36.7)$ & $660(31.9)$ & $145(28.2)$ & \\
\hline Ex-smoker & $215(24.2)$ & $620(26.1)$ & $541(26.2)$ & $155(30.2)$ & \\
\hline Current smoker & $327(36.8)$ & $885(37.2)$ & $867(41.9)$ & $214(41.6)$ & \\
\hline Habit of exercise & $131(14.7)$ & $462(19.4)$ & $416(20.1)$ & $107(20.8)$ & 0.003 \\
\hline Alcohol consumption, g/wk & $44.4(54.3)$ & $51.0(56.6)^{\dagger}$ & $57.9(59.0)^{\mathrm{t}, *}$ & $64.7(61.5)^{+, *}$ & $<0.001$ \\
\hline Women & & & & & \\
\hline Sleep duration (h) & $\leq 5 \mathrm{~h}$ & $>5-6$ & $>6-7$ & $>7$ & $\mathrm{p}$ value \\
\hline Number & 1,039 & 2,733 & 2,128 & 558 & \\
\hline Age (years) & $43.1(8.5)$ & $41.7(8.3)^{\dagger}$ & $41.1(8.3)^{\dagger, ~}$ & $39.8(8.8)^{+\neq, \downarrow, 8}$ & $<0.001$ \\
\hline Body mass index $\left(\mathrm{kg} / \mathrm{m}^{2}\right)$ & $20.9(2.8)$ & $20.8(2.6)$ & $20.5(2.4)^{+, \ddagger}$ & $20.4(2.5)^{\dagger, \ldots, s}$ & $<0.001$ \\
\hline Body mass index categories & & & & & $<0.001$ \\
\hline Lean & $183(17.6)$ & $481(17.6)$ & $443(20.8)$ & $129(23.1)$ & \\
\hline Normal body weight & $649(62.5)$ & $1,783(65.2)$ & $1,390(65.3)$ & $353(63.3)$ & \\
\hline Overweight & $129(12.4)$ & $301(11.0)$ & $194(9.1)$ & $51(9.1)$ & \\
\hline Obesity & $78(7.5)$ & $168(6.1)$ & $101(4.7)$ & $25(4.5)$ & \\
\hline Systolic blood pressure (mmHg) & $108.6(13.8)$ & $109.0(13.7)$ & $108.5(13.6)$ & $108.4(13.2)$ & 0.521 \\
\hline Diastolic blood pressure (mmHg) & $67.0(9.4)$ & $67.5(9.4)$ & $67.2(9.1)$ & $67.0(9.0)$ & 0.412 \\
\hline Fasting plasma glucose $(\mathrm{mmol} / \mathrm{L})$ & $5.0(0.4)$ & $5.0(0.5)$ & $5.0(0.4)^{\dagger}$ & $4.9(0.4)^{\dagger}$ & 0.003 \\
\hline HbAlc (\%) & $5.2(0.3)$ & $5.2(0.4)$ & $5.2(0.4)^{\dagger, *}$ & $5.1(0.4)$ & $<0.001$ \\
\hline $\mathrm{TG}(\mathrm{mmol} / \mathrm{L})$ & $0.6(0.4)$ & $0.7(0.4) \dagger$ & $0.7(0.4)^{\dagger}$ & $0.7(0.4)$ & 0.006 \\
\hline HDL cholesterol (mmol/L) & $1.7(0.4)$ & $1.6(0.4) \dagger$ & $1.6(0.4)^{\dagger}$ & $1.6(0.4)^{\mathrm{t}, \mathrm{t}}$ & $<0.001$ \\
\hline TG/HDL cholesterol ratio & $0.41(0.43)$ & $0.46(0.38)^{\dagger}$ & $0.46(0.33)^{\dagger}$ & $0.47(0.32)^{\dagger}$ & $<0.001$ \\
\hline Creatinine $(\mu \mathrm{mol} / \mathrm{L})$ & $59.7(6.5)$ & $61.3(10.0)^{\dagger}$ & $61.4(10.0)^{\dagger}$ & $60.6(9.7)$ & $<0.001$ \\
\hline $\mathrm{eGFR}\left(\mathrm{ml} / \mathrm{min} / 1.73 \mathrm{~m}^{2}\right)$ & $77.1(14.4)$ & $75.8(14.5)$ & $76.1(14.8)$ & $77.9(14.8)^{\ddagger .9}$ & 0.004 \\
\hline AST (IU/L) & $16.5(5.4)$ & $16.2(14.5)$ & $16.1(13.2)$ & $16.0(5.2)$ & 0.723 \\
\hline $\operatorname{ALT}(\mathrm{IU} / \mathrm{L})$ & $14.6(6.9)$ & $14.0(5.9)$ & $14.0(19.0)$ & $14.0(8.0)$ & 0.599 \\
\hline GGT (IU/L) & $12.9(6.8)$ & $12.6(8.6)$ & $12.3(9.1)$ & $11.8(6.6)^{\dagger}$ & 0.039 \\
\hline
\end{tabular}




\begin{tabular}{lccccc}
\hline Table II (continued) & \multicolumn{5}{l}{} \\
\hline Smoking status & $872(83.9)$ & $2,378(87.0)$ & $1,887(88.7)$ & $489(87.6)$ & \\
Never smoker & $79(7.6)$ & $176(6.4)$ & $129(6.1)$ & $32(5.7)$ & \\
Ex-smoker & $88(8.5)$ & $179(6.6)$ & $112(5.3)$ & $37(6.6)$ & \\
Current smoker & $131(12.6)$ & $445(16.3)$ & $340(16.0)$ & $73(13.1)$ & 0.011 \\
Habit of exercise & $13.3(28.7)$ & $13.4(28.5)$ & $13.5(27.8)$ & $11.2(26.0)$ & 0.373 \\
Alcohol consumption, g/wk &
\end{tabular}

Data are expressed as mean (SD) or number (\%) of subjects. ALT: alanine aminotransferase; AST: aspartate aminotransferase; eGFR: estimated glomerular filtration rate; GGT, gamma-glutamyltransferase; HbAlc: hemoglobin Alc; HDL: high-density lipoprotein; TG: triglycerides. Lean was defined $<18.5 \mathrm{~kg} / \mathrm{m}^{2}$, normal body weight was defined $\geq 18.5-<23 \mathrm{~kg} / \mathrm{m}^{2}$, overweight was defined $\geq 23-<25 \mathrm{~kg} / \mathrm{m}^{2}$ and obesity was defined $\geq 25 \mathrm{~kg} / \mathrm{m}^{2}$. p values by one-way analysis of variance for continuous variables and chi-squared test for categorical variables. The analyses of continuous among four groups were „performed by Tukey HSD test: ${ }^{\dagger}, \mathrm{p}<0.05$ versus sleep duration $\leq 5 \mathrm{~h},{ }^{*}, \mathrm{p}<0.05$ versus sleep duration $>5-6 \mathrm{~h},{ }^{\text {s; }} \mathrm{p}<0.05$ versus sleep duration $>6-7 \mathrm{~h}$.

During the median 6.8-year follow-up for men and 7.0-year follow-up for women, 2,280 participants (1,581 men and 699 women) developed NAFLD. The 5 years cumulative incident rates of NAFLD were $23.5 \%$ for men and $6.8 \%$ for women with a sleep duration of $\leq 5 \mathrm{~h}, 19.4 \%$ for men and $6.3 \%$ for women with sleep duration of $>5-6 \mathrm{~h}, 17.3 \%$ for men and $4.9 \%$ for women with sleep duration of $>6-7 \mathrm{~h}$ and $17.2 \%$ for men and $4.8 \%$ for women with sleep duration of $>7 \mathrm{~h}$. Compared with the longest sleep duration group, the shortest sleep duration group was associated with a higher risk of incident NAFLD in both men ( $p=0.007)$ and women ( $=0.005)$ (Figs. 2 and 3$)$.

According to the Cox proportional hazards models, the shortest sleep duration was revealed to be a significant risk for incident NAFLD, compared to the longest sleep duration (men; hazard ratio [HR] 1.39, 95\% confidence interval [95\%CI] 1.13$1.72, \mathrm{p}=0.002$, women; HR 1.46, 95\%CI 1.05-2.04, $\mathrm{p}=0.023$ ) (Table III). Apart from sleep duration, BMI was a significant

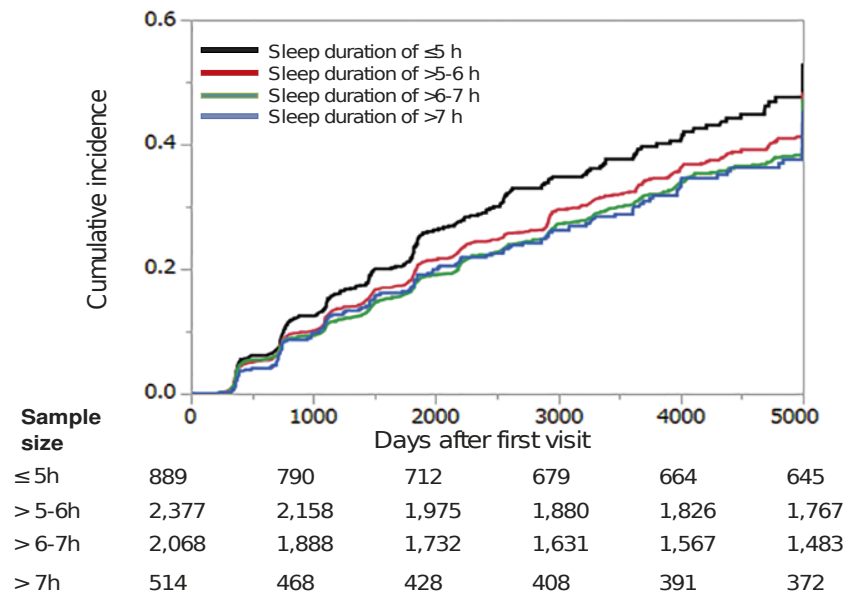

Fig. 2. Kaplan-Meier analysis of incident NAFLD in men. The vertical axis is cumulative incidence of NAFLD and the horizontal axis is time as days. $\log$ rank test to sleep duration of $\leq 5 \mathrm{~h}$, sleep duration of $>5-6 \mathrm{~h} ; \mathrm{p}=0.014$, sleep duration of $>6-7 \mathrm{~h} ; \mathrm{p}<0.001$, sleep duration of $>7 \mathrm{~h} ; \mathrm{p}=0.007, \log$ rank test compared to sleep duration of $5-6 \mathrm{~h}$, sleep duration of $>6-7 \mathrm{~h} ; \mathrm{p}=0.183$, sleep duration of $>7 \mathrm{~h} ; \mathrm{p}=0.283$, log rank test compared to sleep duration of 6-7 h, sleep duration of $>7 \mathrm{~h} ; \mathrm{p}=0.773$. Log rank tests were performed to investigate the association among the groups of sleep duration. Bonferroni correction was performed to correct familiar error and a $\mathrm{p}$ value $<0.0083$ was considered statistically significant.

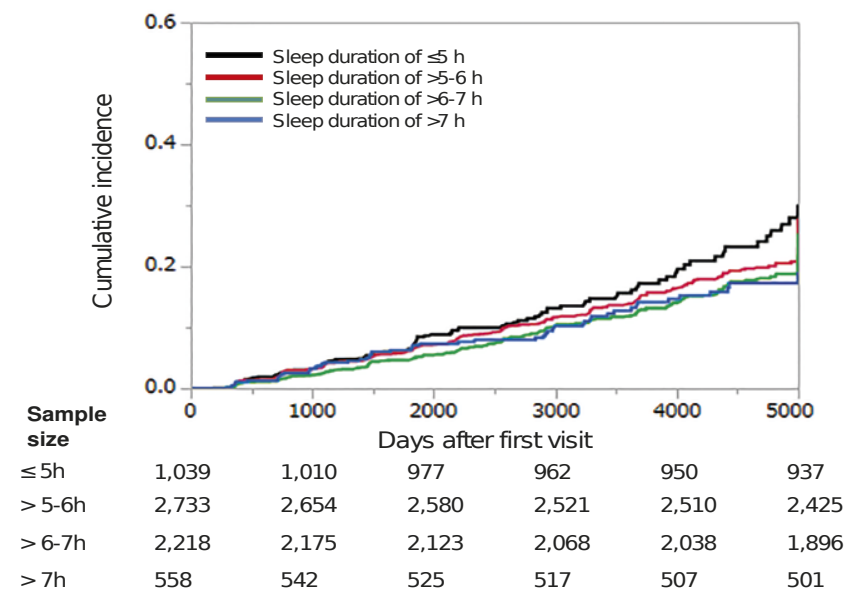

Fig. 3. Kaplan-Meier analysis of incident NAFLD in women. The vertical axis is cumulative incidence of NAFLD and the horizontal axis is time as days. Log rank test compared to sleep duration of $\leq 5 \mathrm{~h}$, sleep duration of $>5-6 \mathrm{~h} ; \mathrm{p}=0.249$, sleep duration of $>6-7 \mathrm{~h} ; \mathrm{p}=0.007$, sleep duration of $>7 \mathrm{~h} ; \mathrm{p}=0.005$, log rank test compared to sleep duration of 5-6 h, sleep duration of $>6-7 \mathrm{~h} ; \mathrm{p}=0.065$, sleep duration of $>7 \mathrm{~h} ; \mathrm{p}=0.123$, log rank test compared to sleep duration of 6-7 h, sleep duration of $>7 \mathrm{~h} ; \mathrm{p}=0.630$. Log rank tests were performed to investigate the association among the groups of sleep duration. Bonferroni correction was performed to correct familiar error and a $p$ value $<0.0083$ was considered statistically significant.

risk for incident NAFLD. Compared to lean subjects, the other participants, even those with normal body weight, had a significant risk for incident NAFLD (men: normal; hazard ratio [HR] 1.62, 95\% confidence interval [95\%CI] 1.20-2.20, $\mathrm{p}=0.002$, overweight; HR 2.57, 95\%CI 1.88-3.52, $\mathrm{p}<0.001$, obesity; HR 3.56, 95\%CI 2.57-4.93, p <0.001, women: normal; HR 4.30, 95\%CI 2.73-6.75, $\mathrm{p}<0.001$, overweight; HR 9.38, 95\%CI 5.84-15.1, p <0.001, obesity; HR 17.0, 95\%CI 10.5-27.5, $\mathrm{p}<0.001$ ). In addition, even if we used BMI and sleep duration as continuous variables in the Cox proportional hazards models, short sleep duration was a significant risk for incident NAFLD both in men and women (men; hazard ratio [HR] 0.91, $95 \%$ confidence interval $[95 \% \mathrm{CI}] 0.84-0.99, \mathrm{p}=0.045$, women; HR $0.90,95 \%$ CI $0.85-0.96, \mathrm{p}<0.001)$.

\section{DISCUSSION}

We investigated whether short sleep duration was a risk of incident NAFLD using a cohort study of over 12,000 Japanese 
Table III. Cox proportional hazards for incident NAFLD

\begin{tabular}{|c|c|c|c|c|}
\hline & \multicolumn{2}{|l|}{ Men } & \multicolumn{2}{|l|}{ Women } \\
\hline & HR (95\%CI) & $\mathrm{p}$ value & HR (95\%CI) & $\mathrm{p}$ value \\
\hline Age, years & $1.01(0.99-1.01)$ & 0.117 & $1.02(1.01-1.03)$ & $<0.001$ \\
\hline Lean & 1.00 (Reference) & - & 1.00 (Reference) & - \\
\hline Normal & $1.62(1.20-2.20)$ & 0.002 & $4.30(2.73-6.75)$ & $<0.001$ \\
\hline Overweight & $2.57(1.88-3.52)$ & $<0.001$ & $9.38(5.84-15.1)$ & $<0.001$ \\
\hline Obesity & $3.56(2.57-4.93)$ & $<0.001$ & $17.0(10.5-27.5)$ & $<0.001$ \\
\hline $\mathrm{ALT}, \mathrm{IU} / \mathrm{L}$ & $1.01(1.01-1.02)$ & $<0.001$ & $1.00(0.99-1.00)$ & 0.138 \\
\hline Triglycerides, mmol/L & $1.21(1.14-1.28)$ & $<0.001$ & $1.48(1.26-1.75)$ & $<0.001$ \\
\hline $\mathrm{HDL}, \mathrm{mmol} / \mathrm{L}$ & $0.55(0.46-0.67)$ & $<0.001$ & $0.45(0.35-0.58)$ & $<0.001$ \\
\hline Fasting plasma glucose, $\mathrm{mmol} / \mathrm{l}$ & $1.01(1.00-1.02)$ & $<0.001$ & $1.01(1.01-1.02)$ & $<0.001$ \\
\hline Systolic blood pressure, $\mathrm{mmHg}$ & $1.01(1.01-1.02)$ & 0.001 & $1.01(1.00-1.02)$ & $<0.001$ \\
\hline Alcohol consumption, g/wk & $0.99(0.99-1.00)$ & $<0.001$ & $0.99(0.99-1.00)$ & 0.064 \\
\hline Never smoker & 1.00 (Reference) & - & 1.00 (Reference) & - \\
\hline Ex-smoker & $1.01(0.89-1.16)$ & 0.846 & $0.66(0.42-0.96)$ & 0.03 \\
\hline Current smoker & $0.98(0.87-1.10)$ & 0.738 & $1.21(0.90-1.60)$ & 0.195 \\
\hline Regular exerciser & $0.80(0.69-0.92)$ & 0.001 & $0.86(0.69-1.06)$ & 0.151 \\
\hline Sleep duration $(\leq 5 \mathrm{~h})$ & $1.39(1.13-1.72)$ & 0.002 & $1.46(1.05-2.04)$ & 0.023 \\
\hline Sleep duration $(>5-6 h)$ & $1.14(0.95-1.37)$ & 0.169 & $1.20(0.91-1.61)$ & 0.208 \\
\hline Sleep duration $(>6-7 h)$ & $1.05(0.88-1.27)$ & 0.569 & $1.07(0.81-1.45)$ & 0.64 \\
\hline Sleep duration $(>7 \mathrm{~h})$ & 1.00 (Reference) & - & 1.00 (Reference) & - \\
\hline
\end{tabular}

ALT: alanine aminotransferase; HDL: high-density lipoprotein; NAFLD: non-alcoholic fatty liver disease. Lean was defined body mass index (BMI) $<18.5 \mathrm{~kg} / \mathrm{m}^{2}$, normal body weight was defined BMI $\geq 18.5-<23 \mathrm{~kg} / \mathrm{m}^{2}$, overweight was defined BMI $\geq 23-<25 \mathrm{~kg} / \mathrm{m}^{2}$ and obesity was defined BMI $\geq 25 \mathrm{~kg} / \mathrm{m}^{2}$.

participants. Our analyses revealed that the risk of incident NAFLD was significantly higher in participants with short sleep duration of $\leq 5 \mathrm{~h}$ than in those with sleep duration of $>7 \mathrm{~h}$, in both men and women. Previous meta-analysis revealed that short sleep duration was associated with higher prevalence of NAFLD. Moreover, several previous studies reported that short sleep duration was associated with the risk of incident obesity [2], hypertension [3], diabetes, metabolic syndrome [4] and cardiovascular disease [5]. To the best of our knowledge, our study is the first report to reveal that short sleep duration is a risk for incident NAFLD.

To support our findings, some potential explanations are proposed. Obesity and weight gain, both of which play key roles in the pathogenesis of NAFLD [28-30], were associated with short sleep duration by previous studies. In this study, both men and women with short sleep duration had higher BMI than the others. Moreover, short sleep duration was associated with decreased leptin [31, 32] and increased ghrelin [32], which influenced appetite, energy balance and weight gain $[9,10]$. Decreased leptin levels increase appetite and causes obesity [33]. Increased ghrelin causes obesity by increasing dietary intake and decreasing fat utilization [34]. Furthermore, higher levels of inflammatory cytokines such as tumor necrosis factor-alpha and interleukin-6, involved in the pathogenesis of NAFLD, were detected in subjects with a short sleep duration [35-37]. Furthermore, short sleep duration was also reported to enhance the circadian misalignment cortisol [38] and hypothalamic-pituitary-adrenal axis stress [39]. Chronic overactivity in the hypothalamic-pituitary-adrenal axis leads to subclinical hypercortisolism that might be implicated in the development of NAFLD [40]. Previous studies also revealed that lifestyle is closely associated with sleep duration. In fact, individuals with a short sleep duration had dinner at late-night [8], which was a risk of hyperglycemia [41] or obesity [42]. To summarize all these findings, short sleep duration could be a risk of incident NAFLD.

The strengths of our study include using the same standardized diagnosis of fatty liver [22] and the standardized questionnaire for lifestyle factors, and the relatively large population-based longitudinal research. Our study also has some limitations. First, fatty liver was diagnosed by ultrasonography in this population. This may be inaccurate compared to liver biopsy, but ultrasonography detecting fatty liver is the common acceptance by authorities in the epidemiological studies [43]. Second, short sleep duration was reported to be associated with increased energy intake [44], which is well known to be the risk of incident NAFLD [45]. Unfortunately, however, we did not have the data of dietary intake and could not evaluate the association between sleep duration and dietary intake. Third, we did not investigate sleep quality. Poor sleep quality is associated with the prevalence of NAFLD [46]. Similarly, the symptoms such as sleep apnea and loud snoring suggestive of obstructive sleep apnea syndrome (OSAS) were found to be associated with NAFLD [47]. The physical activity links the OSAS and obesity. The association between physical activity and BMI or obesity has been reported 
$[48,49]$. Moreover, OSAS is associated with physical activity [50]. In addition, OSAS is caused by intermittent hypoxia and chronic inflammation via visceral fat obesity [51], similar to the development of NAFLD [52]. We did not have detail data on physical activity and OSAS in this study. We checked only the sleep duration from the questionnaire and did not evaluate the wake-up time, bedtime and shift pattern such as shift workers or day workers. Altered sleep timing was reported to affect increased energy intake [53], and a previous study revealed the association between shift work and metabolic syndrome [54]. In addition, insomia and mental illness such as depression or anxiety has been reported to be related to each other [55]. We did not evaluate the medical history of mental illness; however, we excluded the participants who used any kind of medication, including medication for mental illness. Fourth, several previous studies revealed U-shaped association of sleep duration with mortality [5], cardiovascular disease [4], stroke [56] and metabolic syndrome [4]. We could not evaluate $\mathrm{U}$-shaped association of sleep duration with incident NAFLD, as only 70 participants reported sleep duration more than 8.5 $\mathrm{h}$ in our study. Therefore, we could not accurately evaluate incident NAFLD in the long sleep duration group. Even when we excluded the participants in whom sleep duration was more than $8.5 \mathrm{~h}$, the shortest sleep duration group was a significant risk for incident NAFLD, compared to the longest sleep duration group (men; hazard ratio [HR] 1.40, 95\% confidence interval [95\%CI] 1.13-1.73, p=0.002, women; HR 1.36, 95\%CI $1.08-1.73$, p=0.010). Fifth, we do not have data regarding insulin resistance, which plays a key role in fatty liver disease $[57,58]$. If we could have evaluated insulin resistance, we could have more accurately evaluated the relationship between sleep duration and insulin resistance in the development of NAFLD. Sixth, we had a limited ability to examine different levels of physical activity on incident NAFLD. If we can evaluate the frequency and intensity of exercise, more accurate analysis becomes possible. Lastly, the generalizability of our study to non-Japanese populations is uncertain.

\section{CONCLUSION}

Short sleep duration $(<5 \mathrm{~h})$ presented a risk of incident NAFLD. For the prevention of incident NAFLD, we should encourage patients to have appropriate sleep duration.

Conflicts of interest: Y. H received grants from the Japan Society for the Promotion of Science, Asahi Kasei Corporation, MSD K.K., and the Fuji Foundation for Protein Research, outside the submitted work. M. F received grants from the Japan Society for the Promotion of Science, AstraZeneca plc, Astellas Pharma Inc., Nippon Boehringer Ingelheim Co., Ltd., Daiichi Sankyo Co., Ltd., Eli Lilly Japan K.K., Kyowa Hakko Kirin Co. Ltd., Kissei Pharmaceutical Co., Ltd., MSD K.K., Mitsubishi Tanabe Pharma Corp., Novo Nordisk Pharma Ltd., Sanwa Kagaku Kenkyusho Co., Ltd., Sanofi K.K., Ono Pharmaceutical Co., Ltd, and Takeda Pharmaceutical Co., Ltd., outside the submitted work. The sponsors were not involved in the study design, in the collection, analysis, interpretation of data, in the writing of this manuscript or in the decision to submit the article for publication. These authors declared that although they are affiliated with a department that is supported financially by pharmaceutical companies, the authors received no current funding for this study, and this does not alter their adherence to all journal policies on sharing data and materials. The other authors have nothing to disclose.

Authors' contributions: T.O. contributed to data research and analyses and wrote the manuscript. Y.H. originated and designed the study, analyzed data and reviewed the manuscript for intellectual content. M.H. contributed to the manuscript organization and reviewed and edited the manuscript. A.O. and T.K. originated the study, analyzed the data and contributed to the discussion. M.F. analyzed the data and reviewed and edited the manuscript. H.M. is guarantor of this work and, as such, had full access to all of the data in the study and takes responsibility for the integrity of the data and the accuracy of the data analysis. All authors approved the manuscript's final version.

Funding: This research did not receive any specific grant.

\section{REFERENCES}

1. Ministry of Health Labor and Welfare. Vital statistics in Japan. 2017. Accessed Feb 18, 2019. Available at: https://www.mhlw.go.jp/stf/ houdou/0000177189_00001.html

2. Vgontzas AN, Fernandez-Mendoza J, Miksiewicz T, et al. Unveiling the longitudinal association between short sleep duration and the incidence of obesity: the Penn State Cohort. Int J Obes (Lond) 2014;38:825-832. doi:10.1038/ijo.2013.172

3. Gangwisch JE, Heymsfield SB, Boden-Albala B, et al. Short Sleep Duration as a Risk Factor for Hypertension: Analyses of the First National Health and Nutrition Examination Survey. Hypertension 2006;47:833-839. doi:10.1161/01.HYP.0000217362.34748.e0

4. Ohkuma T, Fujii H, Iwase M, et al. U-shaped association of sleep duration with metabolic syndrome and insulin resistance in patients with type 2 diabetes: The Fukuoka Diabetes Registry. Metabolism 2014;63:484-491. doi:10.1016/j.metabol.2013.12.001

5. Yin J, Jin X, Shan Z, et al. Relationship of Sleep Duration With AllCause Mortality and Cardiovascular Events: A Systematic Review and Dose-Response Meta-Analysis of Prospective Cohort Studies. J Am Heart Assoc 2017;6:e005947. doi:10.1161/JAHA.117.005947

6. Breslau N, Roth T, Rosenthal L, Andreski P. Sleep disturbance and psychiatric disorders: a longitudinal epidemiological study of young adults. Biol Psychiatry 1996;39:411-418. doi:10.1016/00063223(95)00188-3

7. Atkinson G, Fullick S, Grindey C, Maclaren D. Exercise, energy balance and the shift worker. Sports Med 2008;38:671-685. doi:10.2165/00007256-200838080-00005

8. Sakai R, Hashimoto Y, Ushigome E, et al. Late-night-dinner is associated with poor glycemic control in people with type 2 diabetes: The KAMOGAWA-DM cohort study. Endocr J 2017;26;395-402. doi:10.1507/endocrj.EJ17-0414

9. Taheri S, Lin L, Austin D, Young T, Mignot E. Short sleep duration is associated with reduced leptin, elevated ghrelin, and increased body mass index. PLoS Med 2004;1:e62. doi:10.1371/journal.pmed.0010062

10. Stern JH, Grant AS, Thomson CA, et al. Short sleep duration is associated with decreased serum leptin, increased energy intake and decreased diet quality in postmenopausal women. Obesity 2014;22:E55-E61. doi:10.1002/oby.20683

11. Vgontzas AN, Chrousos GP. Sleep, the hypothalamic-pituitaryadrenal axis, and cytokines: multiple interactions and disturbances 
in sleep disorders. Endocrinol Metab Clin North Am 2002;31:15-36. doi:10.1016/S0889-8529(01)00005-6

12. Hamaguchi M, Takeda N, Kojima T, et al. Identification of individuals with non-alcoholic fatty liver disease by the diagnostic criteria for the metabolic syndrome. World J Gastroenterol 2012;18:1508-1516. doi:10.3748/wjg.v18.i13.1508

13. Non-alcoholic Fatty Liver Disease Study Group A, Lonardo A Bellentani S, et al. Epidemiological modifiers of non-alcoholic fatty liver disease: Focus on high-risk groups. Dig Liver Dis 2015;47:997-1006. doi:10.1016/j.dld.2015.08.004

14. Hashimoto Y, Hamaguchi M, Fukuda T, Ohbora A, Kojima T, Fukui M. Fatty liver as a risk factor for progression from metabolically healthy to metabolically abnormal in non-overweight individuals. Endocrine 2017;57:89-97. doi:10.1007/s12020-017-1313-6

15. Fukuda T, Hamaguchi M, Kojima T, et al. The impact of non-alcoholic fatty liver disease on incident type 2 diabetes mellitus in non-overweight individuals. Liver Int 2016;36:275-283. doi:10.1111/liv.12912

16. Musso G, Gambino R, Tabibian JH, et al. Association of non-alcoholic fatty liver disease with chronic kidney disease: a systematic review and meta-analysis. PLoS Med 2014;11:e1001680. doi:10.1371/journal. pmed. 1001680

17. Yoshitaka H, Hamaguchi M, Kojima T, Fukuda T, Ohbora A, Fukui M. Nonoverweight nonalcoholic fatty liver disease and incident cardiovascular disease: A post hoc analysis of a cohort study. Medicine (Baltimore) 2017;96:e6712. doi:10.1097/MD.0000000000006712

18. Kim CW, Yun KE, Jung HS, et al. Sleep duration and quality in relation to non-alcoholic fatty liver disease in middle-aged workers and their spouses. J Hepatol 2013;59:351-357. doi:10.1016/j.jhep.2013.03.035

19. Peng K, Lin L, Wang Z, et al. Short sleep duration and longer daytime napping are associated with non-alcoholic fatty liver disease in Chinese adults. J Diabetes 2017;9:827-836. doi:10.1111/1753-0407.12489

20. Kim D, Kim HJ, Kushida CA, Heo NY, Ahmed A, Kim WR. Short Sleep Duration Is Associated With Abnormal Serum Aminotransferase Activities and Nonalcoholic Fatty Liver Disease. Clin Gastroenterol Hepatol 2017;16:588-590. doi:10.1016/j.cgh.2017.08.049

21. Miyake T, Kumagi T, Furukawa S, et al. Short sleep duration reduces the risk of nonalcoholic fatty liver disease onset in men: a communitybased longitudinal cohort study. J Gastroenterol 2015;50:583-589. doi:10.1007/s00535-014-0989-0

22. Hamaguchi M, Kojima T, Takeda N, et al. The metabolic syndrome as a predictor of nonalcoholic fatty liver disease. Ann Intern Med 2005;143:722-728. doi:10.7326/0003-4819-143-10-200511150-00009

23. Ryu S, Chang Y, Kim DI, Kim WS, Suh BS. Glutamyltransferase as a Predictor of Chronic Kidney Disease in Nonhypertensive and Nondiabetic Korean Men. Clin Chem 2006;53:71-77. doi:10.1373/ clinchem.2006.078980

24. Hamaguchi M, Kojima T, Itoh Y, et al. The severity of ultrasonographic findings in nonalcoholic fatty liver disease reflects the metabolic syndrome and visceral fat accumulation. Am J Gastroenterol 2007;102:2708-2715.

25. Lian Y, Xiao J, Liu Y, et al. Associations between insomnia, sleep duration and poor work ability. J Psychosom Res 2015;78:45-51. doi:10.1016/j. jpsychores.2014.09.009

26. Japan Society for the Study of Obesity. Diagnostic criteria for obesity. Vol. 17. Nihon Himan Gakkai; 2011.

27. Hashimoto Y, Hamaguchi M, Fukuda T, Obora A, Kojima T, Fukui M. Weight gain since age of 20 as risk of metabolic syndrome even in non-overweight individuals. Endocrine 2017;58:253-261. doi:10.1007/ s12020-017-1411-5
28. Okamura T, Hashimoto Y, Hamaguchi M, Obora A, Kojima T, Fukui M. Ectopic fat obesity presents the greatest risk for incident type 2 diabetes: a population-based longitudinal study. Int J Obes (Lond) 2019;43:139148. doi:10.1038/s41366-018-0076-3

29. Patel SR, Hu FB. Short sleep duration and weight gain: a systematic review. Obesity 2008;16:643-653. doi:10.1038/oby.2007.118

30. Hashimoto Y, Hamaguchi M, Fukuda T, et al. BMI history and risk of incident fatty liver: a population-based large-scale cohort study. Eur J Gastroenterol Hepatol 2016;28:1188-1193. doi:10.1097/ MEG.0000000000000682

31. Mullington JM, Chan JL, Van Dongen HP, et al. Sleep loss reduces diurnal rhythm amplitude of leptin in healthy men. J Neuroendocrinol 2003;15:851-854. doi:10.1046/j.1365-2826.2003.01069.x

32. Spiegel K, Tasali E, Penev P, Van Cauter E. Brief communication: Sleep curtailment in healthy young men is associated with decreased leptin levels, elevated ghrelin levels, and increased hunger and appetite. Ann Intern Med 2004;141:846-850. doi:10.7326/0003-4819-141-11200412070-00008

33. Leibel RL. The role of leptin in the control of body weight. Nutr Rev 2002;60:S15-S19. doi:10.1301/002966402320634788

34. DelParigi A, Tschöp M, Heiman ML, et al. High Circulating Ghrelin: A Potential Cause for Hyperphagia and Obesity in Prader-Willi Syndrome. J Clin Endocrinol Metab 2002;87:5461-5464. doi:10.1210/jc.2002020871

35. Prather AA, Marsland AL, Hall M, Neumann SA, Muldoon MF, Manuck SB. Normative variation in self-reported sleep quality and sleep debt is associated with stimulated pro-inflammatory cytokine production. Biol Psychol 2009;82:12-17. doi:10.1016/j.biopsycho.2009.04.008

36. Hotamisligil GS, Arner P, Caro JF, Atkinson RL, Spiegelman BM. Increased adipose tissue expression of tumor necrosis factor-alpha in human obesity and insulin resistance. J Clin Invest 1995;95:2409-2415. doi:10.1172/JCI117936

37. Kern PA, Ranganathan S, Li C, Wood L, Ranganathan G. Adipose tissue tumor necrosis factor and interleukin-6 expression in human obesity and insulin resistance. Am J Physiol Metab 2001;280:E745-E751. doi:10.1152/ajpendo.2001.280.5.E745

38. Wright KP, Drake AL, Frey DJ, et al. Influence of sleep deprivation and circadian misalignment on cortisol, inflammatory markers, and cytokine balance. Brain Behav Immun 2015;47:24-34. doi:10.1016/j. bbi.2015.01.004

39. Minkel J, Moreta M, Muto J, et al. Sleep deprivation potentiates HPA axis stress reactivity in healthy adults. Heal Psychol 2014;33:1430-1434. doi:10.1037/a0034219

40. Targher G, Bertolini L, Rodella S, Zoppini G, Zenari L, Falezza G. Associations between liver histology and cortisol secretion in subjects with nonalcoholic fatty liver disease. Clin Endocrinol (Oxf) 2006;64:337-341. doi:10.1111/j.1365-2265.2006.02466.x

41. Imai S, Kajiyama S, Hashimoto Y, et al. Divided consumption of latenight-dinner improves glycemic excursions in patients with type 2 diabetes: A randomized cross-over clinical trial. Diabetes Res Clin Pract 2017;129:206-212. doi:10.1016/j.diabres.2017.05.010

42. Itani O, Kaneita Y, Murata A, Yokoyama E, Ohida T. Association of onset of obesity with sleep duration and shift work among Japanese adults. Sleep Med 2011;12:341-345. doi:10.1016/j.sleep.2010.09.007

43. Hernaez R, Lazo M, Bonekamp S, et al. Diagnostic accuracy and reliability of ultrasonography for the detection of fatty liver: A metaanalysis. Hepatology 2011;54:1082-1090. doi:10.1002/hep.24452

44. St-Onge MP, Roberts AL, Chen J, et al. Short sleep duration increases energy intakes but does not change energy expenditure in normal- 
weight individuals. Am J Clin Nutr 2011;94:410-416. doi:10.3945/ ajcn.111.013904

45. Zelber-Sagi S, Nitzan-Kaluski D, Goldsmith R, et al. Long term nutritional intake and the risk for non-alcoholic fatty liver disease (NAFLD): A population based study. J Hepatol 2007;47:711-717. doi:10.1016/j.jhep.2007.06.020

46. Kim CW, Yun KE, Jung HS, et al. Sleep duration and quality in relation to non-alcoholic fatty liver disease in middle-aged workers and their spouses. J Hepatol 2013;59:351-357. doi:10.1016/j.jhep.2013.03.035

47. Musso G, Cassader M, Olivetti C, Rosina F, Carbone G, Gambino R. Association of obstructive sleep apnoea with the presence and severity of non-alcoholic fatty liver disease. A systematic review and meta-analysis. Obes Rev 2013;14:417-431. doi:10.1111/obr.12020

48. Bradbury KE, Guo W, Cairns BJ, Armstrong ME, Key TJ. Association between physical activity and body fat percentage, with adjustment for BMI: a large cross-sectional analysis of UK Biobank. BMJ Open 2017;7: e011843. doi:10.1136/bmjopen-2016-011843

49. Chin SH, Kahathuduwa CN, Binks M. Physical activity and obesity: what we know and what we need to know. Obes Rev 2016; 17:12261244. doi:10.1111/obr.12460

50. Aiello KD, Caughey WG, Nelluri B, Sharma A, Mookadam F, Mookadam M. Effect of exercise training on sleep apnea: A systematic review and meta-analysis. Respir Med. 2016;116: 85-92. doi:10.1016/j. rmed.2016.05.015

51. Hashimoto Y, Okamura T, Hamaguchi M, Obora A, Kojima T, Fukui M. Impact of respiratory function on the progression from metabolically healthy non-overweight to metabolically abnormal phenotype. Nutr Metab Cardiovasc Dis 2018;28:922-928. doi:10.1016/j. numecd.2018.05.016

52. Tarantino G, Citro V, Finelli C. What non-alcoholic fatty liver disease has got to do with obstructive sleep apnoea syndrome and viceversa? J Gastrointestin Liver Dis 2014;23:291-299. doi:10.15403/ jgld.2014.1121.233.gvt

53. McNeil J, Doucet É, Brunet JF, et al. The effects of sleep restriction and altered sleep timing on energy intake and energy expenditure. Physiol Behav 2016;164:157-163. doi:10.1016/j.physbeh.2016.05.051

54. Karlsson B, Knutsson A, Lindahl B. Is there an association between shift work and having a metabolic syndrome? Results from a population based study of 27,485 people. Occup Environ Med 2001;58:747-752. doi:10.1136/oem.58.11.747

55. Taylor DJ, Lichstein KL, Durrence HH, Reidel BW, Bush AJ. Epidemiology of insomnia, depression, and anxiety. Sleep 2005;28:14571464. doi:10.1093/sleep/28.11.1457

56. Li W, Wang D, Cao S, et al. Sleep duration and risk of stroke events and stroke mortality: A systematic review and meta-analysis of prospective cohort studies. Int J Cardiol 2016;223:870-876. doi:10.1016/j. ijcard.2016.08.302

57. Finelli C, Tarantino G. What is the role of adiponectin in obesity related non-alcoholic fatty liver disease? World J Gastroenterol 2013;19:802812. doi:10.3748/wjg.v19.i6.802

58. Tarantino G, Finelli C, Colao A, et al. Are hepatic steatosis and carotid intima media thickness associated in obese patients with normal or slightly elevated gamma-glutamyl-transferase? J Transl Med 2012;10:50. doi:10.1186/1479-5876-10-50 